\title{
DO MEN CONFORM MORE THAN WOMEN IN THE RECOGNITION AND LABELING OF EMOTIONS?
}

\author{
Jakub PROCHÁZKA, Marcela LEUGNEROVÁ, Soňa DOČEKALOVÁ, Anna HLAVÁČKOVÁ, \\ Veronika MORHÁČOVÁ, Kateřina NEŠPOROVÁ, Stanislav JEŽEK, Martin VACULÍK \\ Department of Psychology, Faculty of Social Studies, Masaryk University \\ Joštova 10, 60200 Brno, Czech Republic \\ Email: jak.prochazka@mail.muni.cz
}

\begin{abstract}
The study focuses on differences between women and men in recognizing negative emotions from facial expressions and the conformity of women and men while labeling the emotions. Previous research has indicated that women conform more than men when the stimuli used are more comprehensible for men. This research seeks to establish whether this phenomenon can be observed when the stimuli are more comprehensible to women. In this study, 24 women and 25 men labeled the facial expressions of negative emotions, first in private and subsequently in a group with four confederates. In private, women were more successful than men in recognizing facial expressions. However, no differences were observed between women and men in respect to conformity while being in a group. The results show that the displaying of emotions is a gender specific stimulus that does not affect conformity.
\end{abstract}

Key words: conformity, facial expressions, emotion recognition, gender differences, photographs

\section{Do Men Conform More than Women in the Recognition and Labeling of Emotions?}

The aim of this study is a) to verify that women are more successful than men in the recognition of the facial expressions of negative emotions and b) to test whether the facial expressions of negative emotions are gender specific stimuli that lead to the differences in conformity between men and women.

Research on conformity - how people alter their behavior to match the behavior of others (Cialdini \& Goldstein, 2004) - has had

Author's note

The study represents an outcome of a specific research project at Masaryk University, Brno, Czech Republic (MU). a long tradition in psychology. For a long time, women have been considered to be more conformist than men (Endler, Coward, \& Wiesenthal, 1975; Geller, Endler, \& Wiesenthal, 1973; Larsen, 1974; Zikmund, Sciglimpaglia, Lundstrom, \& Cowell, 1984). Meta-analysis conducted by Eagly and Carli (1981) showed that the difference in conformity between men and women exists but is quite small. According to a couple of studies, this difference is moderated by variables such as the gender of other group members (Javornisky, 1979), the order of responses in the group (Eagly \& Chrvala, 1986), and the age of the participants (Eagly \& Carli, 1981; Eagly \& Chrvala, 1986; Pasupathi, 1999). "Women conform more than men" may be a false stereotype, which was supported by studies that favored male respondents because of the presence of moderators that were

DOI: $10.21909 / \mathrm{sp} .2016 .04 .721$ 
more suitable for men. However, there also are recent studies hypothesizing that women generally conform more than men (e.g., Rosander \& Eriksson, 2012).

Why should the gender difference in conformity be a false stereotype? When should women conform less than men? According to Eagly and Carli (1981), conformity findings are also influenced by the gender of the researchers who select the questions and experimental tasks for a given study. A possible explanation of this influence is that tasks and questions could be more convenient and understandable for participants who are of the same gender as the researcher. A suitable formulation of tasks or questions could potentially increase the certainty of participants' responses, and decrease their tendency to rely on external cues and their propensity to conform to others. Women might have been handicapped in past studies because men used to prevail among researchers who designed the studies $(79 \%$ of the authors of influential studies were male according to Eagly and Carli, 1981). This perspective is supported by Sistrunk and McDavid (1971), whose study indicated that women conform more than men only when they judge facts belonging to a typical masculine topic but do not conform more when feminine or neutral topics are used. On the other hand, men conform more under the neutral and feminine topics, and less under the masculine topics. Thus, the differences in conformity between men and women might be the consequence of gender-specific reactions to gender-specific stimuli. Similarly to Sistrunk and McDavid (1971), Lee (2003) studied gender differences in conformity with two distinct sets of questions. In his study women were more conformist than men when asked about sports, yet the exact op- posite was observed when participants were asked about fashion.

Cialdiny and Goldstein (2004) stated that there are three core interrelated motivations for conformity: sustaining a positive selfconcept through agreeing with the majority, maintaining a sense of affiliation through gaining social approval, and increasing the accuracy of one's decisions. The latter motivation might play a pivotal role in the differing level of conformity between genders. While uncertain of their judgments (e.g., because of a question from a topic which is typical for the other gender), individuals might be more prone to conform to others in order to increase the accuracy of their judgments. In both studies (Lee, 2003; McDavid, 1971), authors manipulated the masculinity/ femininity of the stimuli by choosing a masculine or feminine topic of interest (e.g., fashion). Gender differences in the knowledge of the gender-specific topic caused the gender differences in conformity. The question is whether different kinds of masculine/feminine stimuli influence the conformity of women and men similarly. We want to test whether there would be a similar effect if we challenge a gender-specific ability instead of the knowledge of the gender-specific topic.

This gender-specific ability might be emotion recognition. Emotion recognition became a broadly studied topic in psychology in the past years. The research included strong focus on various kinds of interpersonal differences in emotion recognition - e.g., differences between healthy and unhealthy population (e.g., Bora, Velakoulis, \& Walterfang, 2016; Ludlow, Garrood, Lawrence, \& Gutierrez, 2014; Wegbreit et al., 2015), cultural differences (e.g., Gul \& Humphreys, 2014; Prado et al., 2014) and 
there are also a couple of new studies on gender differences. When asked to recognize emotional facial expressions, women are generally faster (Hampson, van Anders, \& Mullin, 2006), more accurate (make fewer errors and distinguish various emotions more easily; Labrecht, Kreifelts, \& Wildgruber, 2014; Lawrence, Cambell, \& Skuse, 2015; Montagne, Kessels, Frigerio, de Haan, \& Perrett, 2005; Thayer \& Johnsen, 2000), and more sensitive (react faster to a shift from a neutral facial expression to an emotional facial expression) (Montagne et al., 2005) than men. Female superiority in this domain has been shown to be particularly true for facial expressions of negative emotions (Hampson et al., 2006). The possible explanation of this difference is that women focus more on eyes while men focus more on mouth when they observe a facial expression (Hall et al., 2010; Sullivan, Cambell, Hutton, \& Ruffiman, 2015). The greater number of visual fixations to the upper portion of faces correlates with better recognition of negative emotions (Wong, Cronin-Golomb, \& Neargarder, 2005). Thus facial expressions of negative emotions might represent a stimulus that is more comprehensible for women than for men and that may cause the observed gender differences in conformity.

We answer two questions and test two hypotheses in this study.

Research question 1: What is the difference in the recognition of facial expressions of negative emotions between men and women?

Hypothesis 1: Women are more successful than men in the recognition of facial expressions of negative emotions.

Research question 2: Do men conform more than women while emotion expression is used as a stimulus?
Hypothesis 2: Men conform more than women while assessing negative facial expressions of other people.

The validity of the first hypothesis is an assumption for testing the second one.

\section{Method}

\section{Participants}

Our sample consisted of 24 female and 25 male university students (age range = 20 -25 years; $M=22, S D=2$ ) from 10 faculties of the Masaryk University and Technical University in Brno, Czech Republic. As it has been previously shown, the age of participants might influence conformity (Endler et al., 1975; Pasupathi, 1999), a homogenous sample in terms of age was recruited. No psychology students were included in the sample as we expected that they could uncover the purpose of the experiment more easily than students of other majors. All participants volunteered in the research based on their response to an advertisement for a study of emotion recognition. The participants were paid approximately 4 euro for their participation. One participant was excluded from the analysis as she did not correctly recognize any of the ten facial expressions in the first phase of the study. That failure might have been caused by low motivation, and including her in our study could have led to potential bias in our results.

\section{Procedure}

Participants were told that they were taking part in a study focused on emotion recognition. In pre-test conditions, they were instructed to assess photographs of facial 
expressions in private and write down their responses in the questionnaire. After finishing the questionnaire, participants were sent to a room at the university where they met four people of the same age, two men and two women, who behaved as if they were participants, but were, in fact, confederates of the researchers. Groups of five were used intentionally as they render enough social influence, which was not shown to substantially increase by adding more members (Asch, 1955). The number of male and female confederates was equal, as the conformity of the men and women could be influenced by unequal gender compositions of the groups.

Upon entering the room, the participant and confederates were asked to take a seat with the number indicated on their questionnaire. Two researchers, a man and a woman, were present in the room. A power point presentation of photographs of facial expressions and multiple-choice questions was projected on a wall. The instruction for the participant and confederates was to select and state out loud which emotion they thought was shown on the wall. The participant and confederates answered in the order that they were seated in. The participant was always seated in the last seat.

All confederates answered identically based on a prior arrangement. When the study was over, the researchers gave the participant a monetary reward, and one of the researchers debriefed the participant. As a part of the debriefing, the participant was informed about the true purpose of the experiment and asked whether the true purpose was uncovered by the participant. No participant stated that he or she was aware of the manipulation.

\section{Material}

The stimulus material consisted of black and white photographs of male and female faces showing different emotions. Photographs of both genders were equally represented. The photographs were selected in a pilot study with 20 participants. All students in the pilot study were presented with 56 photographs. Their task was to assess what emotion is presented in the picture. In the main study, the photographs used were the most ambiguous (received the highest number of various answers), and the correct answer was based on the consensus of participants in the pilot study.

According to Mohoric, Taksic, and Duran (2010), it is highly problematic to determine the correct answer in ability-based tasks related to emotions. In general, three methods can be used: consensus scoring (the correct answer is the most common answer of participants), expert scoring (the correct answer is determined by an expert in the particular field), and planned scoring (the creator of the method decides on the correct answer). As it is difficult to establish who is an expert on emotion recognition (MacCann, Roberts, Matthews, \& Zeinder, 2004), and we did not aspire to assume the expertise, we decided that consensus scoring was the most valid method for our study.

We selected the most ambiguous photographs to allow room for conformity on the part of the participants. We assumed that a selection of unambiguous photographs could lead to a high degree of certainty in the participants, which could manifest itself in a lower level of conformity. Furthermore, participants could have uncovered the true purpose of the experiment more easily. 


\section{Pre-test: Emotion Recognition in Private}

The questionnaire contained ten photographs of male and female faces. The facial expressions reflected one of the three negative emotions: disgust (three times), anger (three times), and sadness (four times). Only negative emotions were included, based on a previous study by Hampson et al. (2006), which showed that differences in performance between men and women are observable for the recognition of facial expressions of negative emotions. Participants were instructed to select which of the listed emotions reflected the facial expression in the picture. Demographic questions were put at the end of the questionnaire.

\section{Post-test: Emotion Recognition in Group and Conformity Assessment}

In the group-pressure condition, the task and photographs were identical to the ones included in the questionnaire. However, an additional 14 photographs were included to disguise the true focus of the study. Participants were again instructed to select one emotion from a list of five emotions. They stated their answer out loud in front of the other group members after all the confeder- ates had given their answer. When the photograph from the questionnaire was used, all the confederates unanimously gave an incorrect answer based on the instructions given prior to the experiment. Participants were assumed to be conforming when their answer was a) in line with the responses of the confederates and b) differed from the answer that the participant gave in the questionnaire. The conformity score was computed as the absolute number of responses in which participants conformed - the score could range from 0 to 10 .

\section{Results}

Our analysis supported our hypothesis that women perform better than men in recognition of facial expressions of negative emotions. On average, women significantly outperformed men (Table 1) with a difference representing a medium effect (Cohen $d=0.7$ ). Thus, for our further analysis, we considered facial expressions of negative emotions as stimuli more comprehensible for women.

Our hypothesis that men conform more than women while assessing the facial expressions of negative emotions was not supported by our analysis. The difference in conformity of women and men was not significant (Table 1).

Table 1 Differences between women and men in recognition of negative facial expressions and conformity while labeling negative facial expressions

\begin{tabular}{|c|c|c|c|c|c|c|c|c|c|}
\hline & \multirow[b]{2}{*}{$N$} & \multicolumn{4}{|c|}{ Emotion recognition } & \multicolumn{4}{|c|}{ Conformity } \\
\hline & & $M$ & $S D$ & $t(47)$ & $p$ & $M$ & $S D$ & $t(47)$ & $p$ \\
\hline Women & 24 & 3.46 & 1.35 & \multirow{2}{*}{2.42} & \multirow{2}{*}{.02} & 3.63 & 1.28 & \multirow{2}{*}{.75} & \multirow{2}{*}{.46} \\
\hline Men & 25 & 2.64 & 0.99 & & & 3.28 & 1.86 & & \\
\hline
\end{tabular}




\section{Discussion}

In line with previous research (Gard \& Kring, 2007; Hampson et al., 2006; Montagne et al., 2005; Thayer \& Johnsen, 2000), our study showed that women outperform men in the recognition of negative facial expressions. However, contrary to our expectations, our study did not reveal any significant difference in conformity between men and women while deducing negative emotions from facial expression and labeling them. Even though this result does not support our hypotheses, it also does not support the general stereotype that women conform more than men do.

Our latter hypothesis was based on the assumption that if the facial expressions of negative emotions are more comprehensible for women than for men, men would be less confident in their responses and more prone to conform to the group. Based on our theoretical framework, two interesting lines of thoughts stemmed from our results that should be answered by further research: men might be less uncertain than women when encountering opposite gender specific stimuli, women might be more prone to conform than men when being uncertain.

It is also possible that challenging ability has a different effect on conformity than challenging knowledge. It may be easier to realize a lack of one's own knowledge than to perceive a low level of one's own ability. On the other hand, it may be easier to be sure of the answer on the knowledge question than to be confident in the ability test. Thus, there might be smaller differences in uncertainty between people with different level of ability (e.g., between men and women in emotion recognition) than between people with dif- ferent levels of knowledge. That is why challenging ability might not lead to significant difference in conformity. Further research should control for the level of uncertainty and for the individual level of knowledge and/or ability.

Another possible explanation for our result is connected with the first two core motivations for conformity that we mentioned above (Cialdiny \& Goldstein, 2004): a) sustaining a positive self-concept through agreeing with the majority and b) maintaining a sense of affiliation through gaining social approval. There might be a difference between men and women in the need for social approval and/or in the tendency to agree with the majority. This difference could counteract the effect of uncertainty and lead to not finding the gender difference in conformity. We need further research on gender difference in motivation for conformity to be sure about this explanation.

In order to establish the correct answer as to which emotions are represented by facial expressions, we followed the consensus of the participants in the pilot study. This consensus may mark not the correct answer, but only an opinion of the majority (we cannot know exactly what the photographed person felt). According to this explanation, women are not better at the recognition of negative emotions, but they are better at labeling emotion in consonance with the majority. In this case, facial expressions of negative emotions would not be a feminine stimulus and, thus, our further analysis of conformity could not yield the anticipated results. However, this interpretation would not be in line with the results of previous studies, which indicate that facial expressions are indeed more comprehensible for women than for men (e.g., Gard \& Kring, 2007; Hampson 
et al., 2006; Montagne et al., 2005; Thayer \& Johnsen, 2000).

Particular challenges to the internal validity of our research were posed by external variables that might have influenced the level of conformity. To preclude this, groups of an optimal size and an equal number of men and women in the group were used. Participants from both groups were approached in the same manner, selected from the same sample pool, and underwent the same research procedure. Furthermore, both groups were highly homogenous in terms of age and education. We presume that the influence of gender nonspecific variables that could potentially affect conformity was minimized across both groups.

Some caution should be taken while generalizing our results beyond the population of university students. Our results should be interpreted with respect to some specifics of our sample. In particular, university students are, in general, more intelligent than the rest of the population; intelligence was shown to negatively correlate with conformity (Crutchfield, 1955). Furthermore, the ability to solve problems, even when not taking intelligence into account, is negatively associated with conformity(Nakamura, 1958). Thus, the participants in our research could have been less inclined to conform than the general population. Toincrease the external validity of our findings, replication of our research with a sample from other populations would be needed-preferably with a sample of participants that would be prone to conform more. Additionally, future research should use stimuli which challengeother abilities that are more comprehensible either for men or for women. If such research did not show that men conform more than women when feminine stimuli are used, it would be fruitful to ascer- tain whywomen conform more than men when masculine stimuliare used.

Received October 5, 2015

\section{References}

Asch, S. E. (1955). Opinions and social pressure. Scientific American, 193(5), 31-35.

Bora, E., Velakoulis, D., \& Walterfang, M. (2016). Meta-analysis of facial emotion recognition in behavioral variant frontotemporal dementia: Comparison with Alzheimer disease and healthy controls. Journal of Geriatric Psychiatry and Neurology. Published online first at http:// jgp.sagepub.com.

Cialdini, R. B., \& Goldstein, N. J. (2004). Social influence: Compliance and conformity. Annual Review of Psychology, 55, 591-621. doi: 10.1146/ annurev.psych.55.090902.142015

Crutchfield, R. S. (1955). Conformity and Character. American Psychologist, 10(5), 191-198. doi: $10.1037 / \mathrm{h} 0040237$

Eagly, A. H., \& Carli, L. L. (1981). Sex of researchers and sex-typed communications as determinants of sex differences in influence ability: A meta-analysis of social influence studies. Psychological Bulletin, 90(1), 1-20. doi: 10.1037/00332909.90.1.1

Eagly, A. H., \& Chrvala, A. (1986). Sex differences in conformity: Status and gender role interpretations. Psychology of Women Quarterly, 10(3), 203-220. doi: 10.1111/j.1471-6402.1986. tb00747.x

Endler, N. S., Coward, T. R., \& Wiesenthal, D. L. (1975). The effects of prior experience with a task on subsequent conformity to a different task. The Journal of Social Psychology, 95(2), 207219. doi: 10.1080/00224545.1975.9918706

Gard, M. G., \& Kring, A. M. (2007). Sex differences in the time course of emotion. Emotion, 7(2), 429-437. doi: 10.1037/1528-3542.7.2.429

Geller, S. H., Endler, N. S., \& Wiesenthal, D. L. (1973). Conformity as a function of task generalization and relative competence. European Journal of Social Psychology, 3(1), 53-62. doi: $10.1002 /$ ejsp.2420030104

Gul, A., \& Humphreys, G. W. (2014). Cultural effects in emotion and gender recognition. Asian Journal of Social Psychology, 17(1), 70-80. doi: 10.1111/ajsp.12039 
Hall, J. K., Hutton, S. B., \& Morgan, M. J. (2010). Sex differences in scanning faces: Does attention to the eyes explain female superiority in facial expression recognition? Cognition and Emotion, 24, 629-637. doi:10.1080/02699930902906882

Hampson, E., van Anders, S. M., \& Mullin, L. I. (2006). A female advantage in the recognition of emotional facial expressions: Test of an evolutionary hypothesis. Evolution and Human Behaviour, 27(6), 401-416. doi:10.1016/j. evolhumbehav.2006.05.002

Javornisky, G. (1979). Task content and sex differences in conformity. The Journal of Social Psychology, 108(2), 213-220. doi: 10.1080/ 00224545.1979 .9711634

Labrecht, L., Kreifelts, B., \& Wildgruber, D. (2014). Gender differences in emotion recognition: Impact of sensory modality and emotional category. Cognition \& Emotion, 28(3), 452-469. doi: 10.1080/02699931.2013.837378

Larsen, K. S. (1974). Conformity in the Asch experiment. The Journal of Social Psychology, 94(2), 303-304. doi: 10.1080/00224545.1974. 9923224

Lawrence, K., Campbell, R., \& Skuse, D. (2015). Age, gender, and puberty influence the development of facial emotion recognition. Frontiers in Psychology, 6. doi: http://dx.doi.org/10.3389/ fpsyg.2015.00761

Lee, E.-J. (2003). Effect of „gender“ of the computer on informational social influence: The moderating role of task type. International Journal of Human-Computer Studies, 58(4), $347-$ 362. doi:10.1016/S1071-5819(03)00009-0

Ludlow, A. K., Garrood, A., Lawrence, K., \& Gutierrez, R. (2014). Emotion recognition from dynamic emotional displays in children with ADHD. Journal of Social and Clinical Psychology, 33(5), 413-427.

MacCann, C., Roberts, R. D., Matthews, G., \& Zeidner, M. (2004). Consensus scoring and empirical option weighting of performance-based emotional intelligence (EI) tests. Personality and Individual Differences, 36(3), 645-662. doi:10. 1016/S0191-8869(03)00123-5

Mohoric, T., Taksic, V., \& Duran, M. (2010). In search of ,the correct answer" in an abilitybased emotional intelligence (EI) test. Studia Psychologica, 52(3), 219-228.

Montagne, B., Kessels, R. P. C., Frigerio, E., de Haan, E. H. F., \& Perrett, D. I. (2005). Sex differences in the perception of affective facial expressions: Do men really lack emotional sensitivity? Cognitive Processing, 6(2), 136-141. doi: 10.1007/s10339-005-0050-6

Nakamura, C. Y. (1958). Conformity and problem solving. Journal of Abnormal and Social Psychology, 56(3), 315-320. doi: 10.1037/h0041150

Pasupathi, M. (1999). Age differences in response to conformity pressure for emotional and nonemotional material. Psychology and Aging, 14(1), 170-174. doi: 10.1037/0882-7974.14. 1.170

Prado, C., Mellor, D., Byrne, L. K., Wilson, C., $\mathrm{Xu}, \mathrm{X} .$, \& Liu, H. (2014). Facial emotion recognition: A cross-cultural comparison of Chinese, Chinese living in Australia, and Anglo-Australians. Motivation and Emotion, 38(3), 420-428.

Rosander, M., \& Eriksson, O. (2012). Conformity on the Internet - The role of task difficulty and gender differences. Computers in Human Behaviour, 28(5), 1587-1595. doi: 10.1016/j.chb. 2012.03 .023

Sistrunk, F., \& McDavid, J. W. (1971). Sex variable in conforming behaviour. Journal of Personality and Social Psychology, 17(2), 200-207. doi: $10.1037 / \mathrm{h} 0030382$

Sullivan, S., Campbell, A., Hutton, S. B., \& Ruffman, T. (2015). What's good for the goose is not good for the gander: Age and gender differences in scanning emotion faces. The Journals of Gerontology Series B: Psychological Sciences and Social Sciences. 1-6. doi: 10.1093/geronb/gbv033

Thayer, J. F., \& Johnsen, B. H. (2000). Sex differences in judgment of facial affect: A multivariate analysis of recognition error. Scandinavian Journal of Psychology, 41(3), 243-246.

Wegbreit, E., Weissman, A. B., Cushman, G. K., Puzia, M. E., Kim, K. L., Leibenluft, E., \& Dickstein, D. P. (2015). Facial emotion recognition in childhood-onset bipolar I disorder: An evaluation of developmental differences between youths and adults. Bipolar Disorders, 17(5), 471485 .

Wong, B., Cronin-Golomb, A., \& Neargarder, S. (2005). Patterns of visual scanning as predictors of emotion identification in normal aging. $\mathrm{Neu}$ ropsychology, 19, 739-749. doi:10.1037/08944105.19.6.739

Zikmund, W. G., Sciglimpaglia, D., Lundstrom, W. J., \& Cowell, R. G. (1984). The effects of gender and product stereotyping on conformity judgments: An experiment. Advances in Consumer Research, 11, 265-269. 